\title{
El uso escolar de las TIC desde la visión del alumnado de Educación Primaria, ESO y Bachillerato
}

\section{Primary and Secondary Education students' perspectives on the school use of ICT}

\author{
Manuel Area Moreira ${ }^{1}$ \\ manarea@ull.edu.es \\ Olga Cepeda Romero \\ olceper@ull.edu.es \\ LUIS FELICIANO GARCÍA \\ Ifelici@ull.edu.es \\ Universidad de La Laguna, España
}

\begin{abstract}
Resumen:
En este artículo se presentan algunos de los resultados más destacables sobre la visión y opiniones que tienen los estudiantes de Educación Primaria, de la Educación Secundaria Obligatoria y el Bachillerado con relación al uso escolar de las Tecnologías de Información y Comunicación (TIC) en los centros educativos. Para ello se diseñó un estudio de encuesta en el que se utilizó como instrumento de recogida de datos un cuestionario online diseñado ad hoc. La muestra estuvo constituida por más de 4.000 estudiantes de todas las islas de Canarias. Hemos encontrado diferencias significativas en dichas visiones teniendo en cuenta la etapa educativa, el género, y la disponibilidad de tecnologías en el hogar de los estudiantes. Concluimos en que la inmensa mayoría del alumnado de Educación Primaria y Secundaria es una generación familiarizada con la tecnología digital, que está motivada y demanda
\end{abstract}

\begin{abstract}
:
This article reports on the beliefs and opinions that the students of primary and secondary education have regarding the pedagogical use of Information and Communication Technologies (ICT) in schools. For this, a survey study was designed in which an online questionnaire designed ad hoc was used as the instrument for data collection. The sample consisted of more than 4,000 students from all the Canary Islands. We found significant differences regarding the educational stage, gender and the availability of technologies in the students' homes. We concluded that the vast majority of students of Primary and Secondary Education are a generation familiar with digital technology, which is motivated and demands the continued use of ICT in schools, although it maintains a critical vision of the school tasks developed with them and of the degree of digital competence of its teaching staff.
\end{abstract}

1 Dirección para correspondencia (correspondence address):

Manuel Area Moreira. Dpto. de Didáctica e Investigación Educativa. Universidad de la Laguna. Facultad de Educación. C/ Delgado Barreto, s/n. Edificio Central. Apartado 456. 38200 San Cristóbal de La Laguna (España). 
El uso escolar de las TIC desde la visión del alumnado de Educación Primaria, ESO y

Bachillerato

Manuel Area Moreira, Olga Cepeda Romero y luis feliciano garcía

el uso escolar continuado de las $\mathrm{TIC}$, aunque mantiene una visión crítica hacia las tareas escolares desarrolladas con las mismas y del grado de competencia digital de su profesorado.

Palabras clave:

TIC; Alumnado; Escuela Digital; Tecnología Educativa.

Key words:

ICT; Students; Digital School; Educational Technology.

\section{Resumé:}

Dans cet article, nous présentons les résultats les plus intéressants quant à la vision et I'opinion que les élèves de primaire et de secondaire ont sur l'utilisation en milieu scolaire des Technologies de I'Information et de Communication (TIC) dans les établissements éducatifs. Pour cela, nous avons mis en place une étude de recherche à partir d'un questionnaire en ligne élaboré ad hoc. L'échantillon cible est constitué de 4000 élèves provenant de toutes les îles des Canaries. Nous avons rencontré des différences significatives dans cette collecte de visions et d'opinions, tout en tenant compte du niveau d'études, du sexe et de la place des technologies dans le foyer de nos apprenants. Nous en avons conclu que pour la grande majorité, nous nous sommes trouvés face à des élèves de Primaire et de Secondaire qui constituent une génération totalement familiarisée avec la technologie numérique. Une génération motivée qui réclame I'utilisation continue des TIC, bien qu'elle maintienne une vision plutôt critique quant aux activités développées avec les technologies ainsi qu'envers le degré de compétence numérique de la part de leurs professeurs.

Most Clés:

TIC; Étudiants; École numérique; Technologie éducative.

Fecha de recepción: 11-2-2018

Fecha de aceptación: 8-5-2018

\section{Antecedentes y fundamentación teórica}

\section{Las visiones y opiniones de los agentes educativos sobre las TIC}

Distintos estudios internacionales han puesto en evidencia que uno de los factores clave y relevantes de los procesos de integración pedagógica y uso educativo de las tecnologías digitales está vinculado con las creencias y perspectivas que tengan los agentes educativos sobre dicho proceso (Albirini, 2006; Balanskat, Blamire y Kefala, 2006; Drent y Meelissen, 2008). En este sentido, las políticas educativas de dotación e inversión económica en la adquisición y dotación de infraestructuras y recursos tecnológicos a los centros escolares es insuficiente, si no existe paralelamente un cambio de concepciones, opiniones y prácticas del profesorado, equipos directivos y demás agentes de apoyo con relación 
al potencial de cambio e innovación educativa que conlleva la utilización de dichas tecnologías (Sancho y Alonso, 2012; Colás, De Pablos y Pagán, 2018).

Sobre este particular existen numerosos estudios tanto en el contexto español como internacional sobre las opiniones, percepciones y expectativas del profesorado con relación a las TIC. Estos trabajos han abordado distintas cuestiones y temáticas como los modelos didácticos de uso de TIC en el aula (Area, Hernández y Sosa, 2016), las competencias docentes en tecnología digital (Tejedor y Valcárcel, 2006; Vázquez, Sánchez, M. y Frutos, 2017), los relatos de vida docente con TIC (Raquimán, 2014); las tecnoautobiografías de futuros docentes (Sonlleva, Torrego y Martínez, 2017); o el análisis o valoración de programas y políticas educativas desde la visión del profesorado (Sigalés, Mominó, Meneses y Badia,2008; Area, Sanabria, y Vega, 2013; De Pablos, 2015) entre otros. donde encuestaron, en todo el territorio español, a una importante muestra de profesorado, alumnado y equipos directivos de centros escolares.

En dichas publicaciones se ha puesto de manifiesto, con mayor o menor énfasis, que existe una importante vinculación entre la práctica docente con tecnologías y las creencias o concepciones que poseen los docentes con relación a la enseñanza y el aprendizaje, así como que la disponibilidad de abundante tecnología tiende a favorecer la implementación de cambios e innovaciones metodológicas en la enseñanza en el aula. Asimismo, también se ha constatado que el profesorado percibe que el uso didáctico de las TIC tiende a favorecer la motivación e implicación de los estudiantes en las tareas escolares.

Sin embargo, apenas contamos con estudios que hayan explorado el punto de vista y percepción del alumnado con relación al uso escolar de las tecnologías digitales. Entre los pocos existentes a nivel internacional podríamos citar los desarrollados con alumnado de Educación Primaria en Australia (Selwyn, Potter and Cranmer, 2009); en escuelas de Malasia (Umar and Jalil 2012); en Institutos de Secundaria de Ghana (BuabengAndohaand Issifub, 2015), en Serbia (Glusac; Makitan; Karuovic, Radosav, and Milanov, 2015); en alumnado de $5^{\circ}$ y $6^{\circ}$ de Primaria en China (Zhang, H. and Zhu, 2016) o con alumnado de Educación Secundaria en Grecia (Nikolopoulou and Gialamas, 2016).

En el contexto español, pudieran ser referenciados el estudio donde se encuestaba a alumnado de Bachillerato y ESO sobre el uso y opiniones de las TIC en educación (Souto, Jardón, Traver, Solbesy Ramírez, 
El uso escolar de las TIC desde la visión del alumnado de Educación Primaria, ESO y

Bachillerato

Manuel Area Moreira, Olga Cepeda Romero y luis feliciano garcía

2004); el trabajo de Ruiz y Sánchez (2007) o los realizados más recientemente tomando como muestra al alumnado de Educación Secundaria de Solano, González y López (2013); Domínguez; Chica y Hernández (2015) y de la visión del alumnado, comparándola con el profesorado, en un centro de Educación Infantil y Primaria (Conde, Ávila, Núñez y Mirabent, 2015). A éstos habría que sumar el ya citado de Sigalés, Mominó, Meneses y Badia (2008).

\section{La generación de Millenials y generación Z: los cambios socioculturales en los niños y jóvenes de la sociedad digital}

Los actuales estudiantes del sistema escolar que cursan los estudios de Primaria, ESO y Bachillerato responden a lo que, en el contexto internacional, se denomina como generación Z (niños y adolescentes 10-18 años) que representan la primera generación ya nacida en el nuevo siglo XXI y serían la continuación de la conocida como generación de Millenials (jóvenes entre 18-30 años) nacidos entre ambos siglos.

Existen numerosas y variadas publicaciones sobre la utilización y grado de penetración de las TIC en la vida cotidiana de los jóvenes así como sobre sus efectos en las transformaciones de sus prácticas de comunicación e interacción social. Sobre esta temática son relevantes algunas publicaciones realizadas por la Fundación Telefónica como los de Bringué y Sádaba (2009); Reig y Vilches (2013); García Galera, M.C. y Fernández, C. (2016) donde se retratan los nuevos modos, usos y costumbres de niños, adolescentes y jóvenes que están emergiendo con el uso continuado de la comunicación e interacción social en la Red. Otros trabajos en la misma dirección son los de Rodríguez y Megías (2014) y los monográficos de la Revista Estudios de Juventud (Espín, 2015; Espiritusanto, 2016).

En el contexto educativo, se han publicado algunos trabajos en nuestro país como el de López Fernández (2015) sobre la visión que tiene el alumnado de Secundaria con relación a las redes sociales y el interesante trabajo desarrollado en el contexto de la comunidad de Murcia de BaIlesta, Cerezo y Veas (2014) donde exploraron el uso y consumo de las TIC a través de un cuestionario distribuido entre alumnado de la E.S.O. Por su parte, Area, Borrás, y Sannicolás (2015) proponen un modelo de alfabetización de la ciudadanía digital para los jóvenes Millenials.

En síntesis, pudiéramos señalar que las señas de identidad generacio- 
nales de los niños, adolescentes y jóvenes del presente vienen definidas por rasgos como la hiperconectividad entendida como la conexión permanente desde cualquier sitio y en cualquier momento, la tecnodependencia o necesidad de disponer de una tecnología que le permita estar constantemente visible en la red y/o consumir información de la misma, el establecimiento de redes o grupos sociales estables que comparten vivencias de encuentros físicos y virtuales provocando la convivencia entre espacios paralelos y simultáneos, el predominio de formatos de comunicación e intercambio de información de naturaleza audiovisual y mediante microcontenidos (textuales, icónicos, videos, audio,...); la reducción de experiencias culturales con los modos impresos de comunicación y cultura, entre otros.

\section{Diseño y metodología}

\section{El contexto. Las políticas educativas TIC en Canarias: la evaluación del Proyecto TSP (Tecnologías al Servicio de las Personas)}

El contexto socioeducativo donde se ha desarrollado este estudio es el sistema escolar público del archipiélago de Canarias. En esta comunidad autónoma, a lo largo de estas dos últimas décadas, se ha implementado una política educativa continuada destinada a incorporar las TIC al sistema escolar público. Bajo dicha política se han diseñado y puesto en práctica varios programas o planes educativos de amplio calado que movilizaron numerosos recursos tanto materiales como humanos destinados a que las tecnologías digitales sean una realidad en los centros y aulas del sistema educativo público no universitario de Canarias.

El primer macroproyecto de política educativa TIC, que tuvo una vigencia de casi una década (2000-2009), fue el denominado Proyecto Medusa, continuado posteriormente con el programa Clic-Escuela 2.0 (2009-12) incardinado en el Plan Escuela 2.0 impulsado por el Ministerio de Educación del último gobierno socialista. Ambos proyectos facilitaron que las TIC (PCs, miniportátiles, PDI, cañones multimedia) estén disponibles en numerosas aulas y espacios de los centros, que exista conectividad -más o menos plena- a Internet, que el profesorado haya recibido una formación básica sobre el uso de dichas tecnologías, que se hayan generado tanto contenidos digitales como recursos web (blogs, 
El uso escolar de las TIC desde la visión del alumnado de Educación Primaria, ESO y

Bachillerato

Manuel Area Moreira, Olga Cepeda Romero y luis feliciano garcía

wikis, redes) para su uso por el profesorado y centros, que exista una infraestructura de apoyo y solución de problemas técnico, entre otros rasgos.

A los mismos, le siguió el Ilamado Proyecto TSP (Tecnologías al Servicio de las Personas) durante el periodo 2013-16 que continuó en la misma dirección estratégica poniendo el acento no sólo en los aspectos de dotación tecnológica, sino también en los que implican la capacitación de los agentes educativos y en el desarrollo de las aplicaciones, entornos y servicios digitales con fines pedagógicos.

En este contexto, y como acción incardinada en el Proyecto TSP, se convocó concurso público para proceder a la evaluación del proyecto con la finalidad de diagnosticar la situación de integración y uso de las TIC en las escuelas del archipiélago de las Islas Canarias. La evaluación del proyecto TSP se desarrolló a través de cinco estudios con distintas metodologías que exploraron la opinión del profesorado con relación al uso educativo de las TIC; la opinión del alumnado con relación al uso escolar de las TIC; la opinión de los agentes de apoyo (asesores de Centros de Profesorado y de los técnicos del Área de Tecnología Educativa de Canarias); la integración organizativa y pedagógica de las TIC en una muestra de 40 centros educativos del Archipiélago, y la opinión de los coordinadores TIC de centro con relación al uso educativo de las TIC. El diseño y desarrollo de dicha evaluación fue realizado por el grupo de investigación EDULLAB (Laboratorio de Educación y Nuevas Tecnologías).

En este artículo presentamos algunos de los resultados más significativos obtenidos en el estudio segundo de dicha evaluación del proyecto TSP destinado a chequear la opinión del alumnado.

\section{Objetivos}

Este estudio tuvo la finalidad de explorar e identificar las visiones y perspectivas del alumnado de Educación Primaria, Educación Secundaria Obligatoria (ESO) y Bachillerato sobre el uso educativo de las TIC en los centros escolares. Los objetivos específicos fueron:

- Conocer las características personales y académicas del alumnado.

- Analizar sus opiniones sobre la disponibilidad de recursos y servicios TIC en el hogar

- Examinar el tipo de actividades que saben hacer con el ordenador 
- Analizar sus opiniones sobre la disponibilidad de recursos y servicios TIC en el centro

- Conocer el tipo de actividades que hacen con las TIC en el aula

- Conocer sus valoraciones/expectativas sobre el uso de las TIC en el aula

- Analizar sus opiniones sobre el impacto de las TIC sobre su aprendizaje

- Examinar sus opiniones sobre la formación del profesorado y del alumnado en TIC

\section{Sujetos}

El cuestionario fue cumplimentado por un total de 4101 sujetos; el 51\% de la muestra son hombres y el $49 \%$ mujeres (Figura 1).

\section{Género}

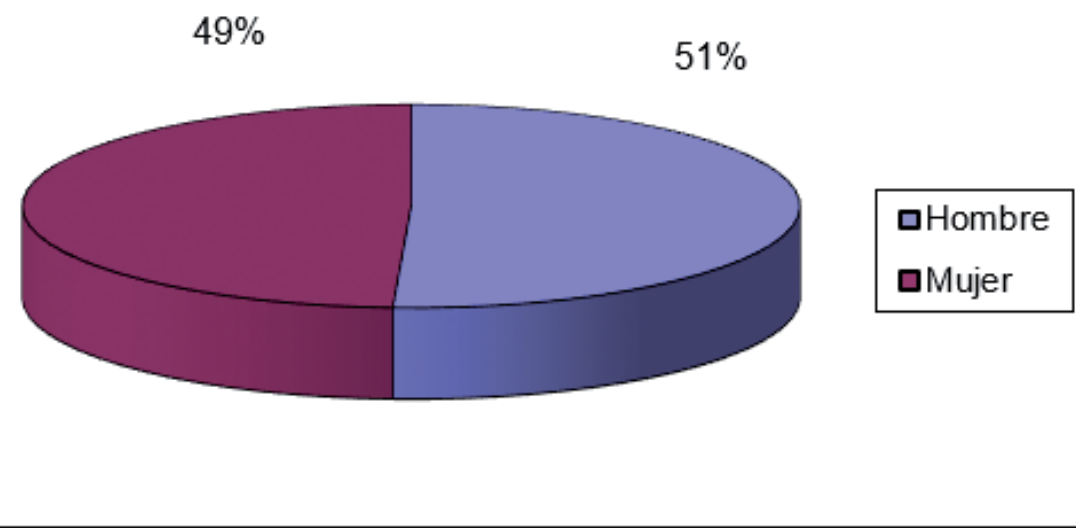

Figura 1. Distribución del alumnado por género.

El mayor porcentaje en la distribución del alumnado por Etapas (figura 2) corresponde a quienes cursan $3^{\circ}-6^{\circ}$ de Primaria (53\%), seguido del alumnado de ESO (39\%) y del alumnado de Bachillerato (8\%). 


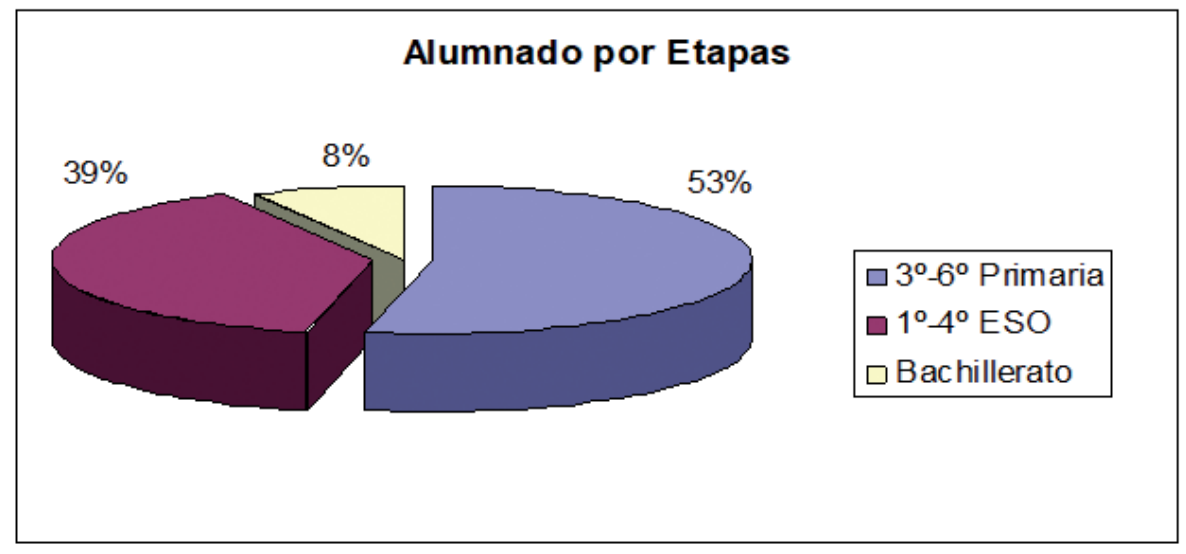

Figura 2. Distribución del alumnado por Etapas.

\section{Instrumento}

Con el objeto de obtener información sobre las dimensiones objeto de estudio se diseñó un cuestionario, formado por 18 ítems de elección múltiple, en los que se abordan cuestiones relativas a las opiniones del alumnado del sistema escolar público de Canarias sobre los recursos y servicios TIC en los centros, las actividades de aula con TIC y sus efectos sobre el aprendizaje. Los ítems que abordan las dimensiones de información y el número de indicadores seleccionados se presentan en la Tabla 1. Este cuestionario fue elaborado por los investigadores y consensuado con los servicios técnicos del Área de Tecnología Educativa (ATE) de la Consejería de Educación del Gobierno de Canarias.

Tabla 1. Ítems e indicadores del cuestionario para cada dimensión de información.

\begin{tabular}{lcl}
\hline Dimensiones de información & Indicadores & Ítems \\
\hline Características personales y académicas & 3 & $1,2,3$ \\
\hline $\begin{array}{l}\text { Disponibilidad de recursos y servicios TIC en el } \\
\text { hogar }\end{array}$ & 7 & 4,5 \\
\hline $\begin{array}{l}\text { Disponibilidad de recursos y servicios TIC en el } \\
\text { centro }\end{array}$ & 6 & 7 \\
\hline $\begin{array}{l}\text { Tipo de actividades que saben hacer con el } \\
\text { ordenador }\end{array}$ & 13 & 6 \\
\hline Actividades que hacen con las TIC en el aula & 14 & 10 \\
\hline
\end{tabular}




\begin{tabular}{lcl}
\hline Dimensiones de información & Indicadores & Ítems \\
\hline $\begin{array}{l}\text { Valoración/preferencias sobre uso de las TIC en } \\
\text { el aula }\end{array}$ & 5 & $8,9,11,14,15$ \\
\hline Impacto de las TIC sobre su aprendizaje & 12 & 12.13 \\
\hline $\begin{array}{l}\text { Opinión sobre competencia digital de profesores } \\
\text { y alumnos }\end{array}$ & 2 & $16,17,18$ \\
\hline
\end{tabular}

\section{Análisis de datos}

El análisis de los datos obtenidos en los cuestionarios comprende tablas de distribución de frecuencias y estadísticos descriptivos para cada una de las variables analizadas. Tablas de Contingencia, Coeficientes chi cuadrado y de Contingencia en función de las siguientes variables: a) Etapas: 4-18; b) sexo: 5, 6, 8, 9, 11, 12, 13, 14, 15, 16; c) Isla: 4, 5, $6,7,16,17,18$; d) Disponibilidad de ordenador para uso personal: 6, 8, $9,11,12,13,14,15,16$. Dichos análisis fueron realizados a través del programa SPSS.19.

\section{Procedimiento}

Los cuestionarios fueron distribuidos y cumplimentados on line. Se difundió a todos los centros escolares públicos de Educación Primaria y Secundaria a través de la Consejería de Educación del Gobierno de Canarias. La recogida de datos se realizó en el curso 2014-15.

\section{Resultados ${ }^{2}$}

La presentación de resultados la realizamos, en primer lugar, con una tabla en la que sintetizamos los resultados globales que hemos encontrado en este estudio (ver tabla 2) para comentar posteriormente algunos de los resultados estadísticamente significativos en función del cruce de variables relativas a la etapa educativa del alumnado, el género, y la disponibilidad de TIC en el hogar.

2 Este apartado está basado en el Informe preliminar de resultados sobre la opinión del alumnado de Educación Primaria, ESO y Bachillerato sobre las TIC elaborado por M. Area (Dir.), L. Feliciano, O. Cepeda y A.B Jiménez para el Proyecto de evaluación del TSP/Área de Tecnología Educativa del Gobierno de Canarias (Documento inédito). 
El uso escolar de las TIC desde la visión del alumnado de Educación Primaria, ESO y Bachillerato

Manuel Area Moreira, Olga Cepeda Romero y luis feliciano garcía

Tabla 2. Síntesis de los resultados globales en función de las dimensiones del estudio.

\begin{tabular}{|c|c|}
\hline $\begin{array}{l}\text { Dimensión de } \\
\text { análisis }\end{array}$ & Resultados globales \\
\hline $\begin{array}{l}\text { Disponibilidad } \\
\text { de recursos y } \\
\text { servicios TIC en } \\
\text { el hogar }\end{array}$ & $\begin{array}{l}\text { Un elevado porcentaje del alumnado encuestado señala que dis- } \\
\text { pone de recursos y servicios TIC en el hogar y de ordenador/Tablet } \\
\text { para uso personal en casa (oscila en torno al } 85 \% \text { ). Sin embargo, } \\
\text { el porcentaje del alumnado que dice disponer de estas tecnolo- } \\
\text { gías en el hogar es mayor en el Bachillerato y ESO que en Prima- } \\
\text { ria. A mayor edad, más disponibilidad de TIC. }\end{array}$ \\
\hline $\begin{array}{l}\text { Disponibilidad } \\
\text { de recursos y } \\
\text { servicios TIC en } \\
\text { el centro }\end{array}$ & $\begin{array}{l}\text { Los datos reflejan unos elevados porcentajes en la consideración } \\
\text { de que los recursos en clase son pocos e inexistentes indepen- } \\
\text { dientemente de la variable de análisis, si bien hay que destacar } \\
\text { que el alumnado de Primaria manifiesta en un } 70 \% \text { que hay } \\
\text { bastantes o muchos ordenadores personales. }\end{array}$ \\
\hline $\begin{array}{l}\text { Tipo de activida- } \\
\text { des que saben } \\
\text { hacer con el or- } \\
\text { denador }\end{array}$ & $\begin{array}{l}\text { La actividad que obtiene un menor porcentaje a la pregunta sobre } \\
\text { qué saben hacer con un ordenador/Tablet es la de escribir en un } \\
\text { blog o en una wiki, independientemente del género, etapa, isla } \\
\text { o disponer o no de ordenador/Tablet para uso personal en casa. }\end{array}$ \\
\hline $\begin{array}{l}\text { Valoración/ex- } \\
\text { pectativas sobre } \\
\text { uso de las TIC } \\
\text { en el aula y ac- } \\
\text { tividades que } \\
\text { hacen con las } \\
\text { mismas }\end{array}$ & $\begin{array}{l}\text { El alumnado manifiesta en un elevado porcentaje su preferencia } \\
\text { por usar las TIC en el aula aunque disminuye a medida que au- } \\
\text { menta la Etapa. Sucede lo mismo con las actividades en grupo. } \\
\text { Aquellos que no disponen de ordenador/Tablet para uso personal } \\
\text { en casa presentan menores porcentajes en su opinión sobre el uso } \\
\text { diario de las TIC en el aula. }\end{array}$ \\
\hline $\begin{array}{l}\text { Impacto de las } \\
\text { TIC sobre su } \\
\text { aprendizaje }\end{array}$ & $\begin{array}{l}\text { A medida que aumenta la edad del estudiante y el nivel de estu- } \\
\text { dios en el que se encuentra disminuye el porcentaje del impacto } \\
\text { del uso de las TIC en el aula sobre el aprendizaje y se incre- } \\
\text { menta a medida que se refieren a actividades más complejas. } \\
\text { Las actividades que obtienen porcentajes más elevados indepen- } \\
\text { dientemente del género son: Escribir textos y trabajos con el or- } \\
\text { denador/Tablet y realizar presentaciones de diapositivas (Power } \\
\text { Point o similares). }\end{array}$ \\
\hline $\begin{array}{l}\text { Opinión sobre } \\
\text { la formación y } \\
\text { competencia di- } \\
\text { gital de profeso- } \\
\text { res y alumnos }\end{array}$ & $\begin{array}{l}\text { El alumnado, en conjunto, opina que los estudiantes tienen un } \\
\text { mayor conocimiento y competencia digital que el profesorado. } \\
\text { Ese porcentaje aumenta en la ESO y el Bachillerato. Es decir, a } \\
\text { mayor edad del alumnado éstos consideran que sus docentes } \\
\text { saben menos de las TIC. También hemos encontrado que menos } \\
\text { de la mitad el alumnado de la ESO y Bachillerato consideran } \\
\text { que los docentes poseen las competencias y conocimientos para } \\
\text { enseñar con TIC. Sin embargo en Ed. Primaria el alumnado per- } \\
\text { cibe que sus docentes son competentes digitalmente y saben } \\
\text { hacer uso educativo de las TIC. }\end{array}$ \\
\hline
\end{tabular}


A continuación presentamos algunos resultados destacables con relación a tres dimensiones de los sujetos: su etapa educativa, su género y la disponibilidad de tecnología en su hogar.

\subsection{Resultados en función de la Etapa: Primaria, ESO y Bachillerato}

VALORACIÓN/EXPECTATIVAS SOBRE EL USO DE LAS TIC EN EL AULA

Se advierte una tendencia relacional estadísticamente significativa entre la etapa cursada y la valoración del uso de las TIC en el aula (Chi cuadrado $\rho<0.000$; Coeficiente de Contingencia: 0.097; $\rho<0.000)$. El alumnado de Educación Primaria realiza valoraciones más positivas que el alumnado de ESO y, sobre todo, en Bachillerato (Figura 3).

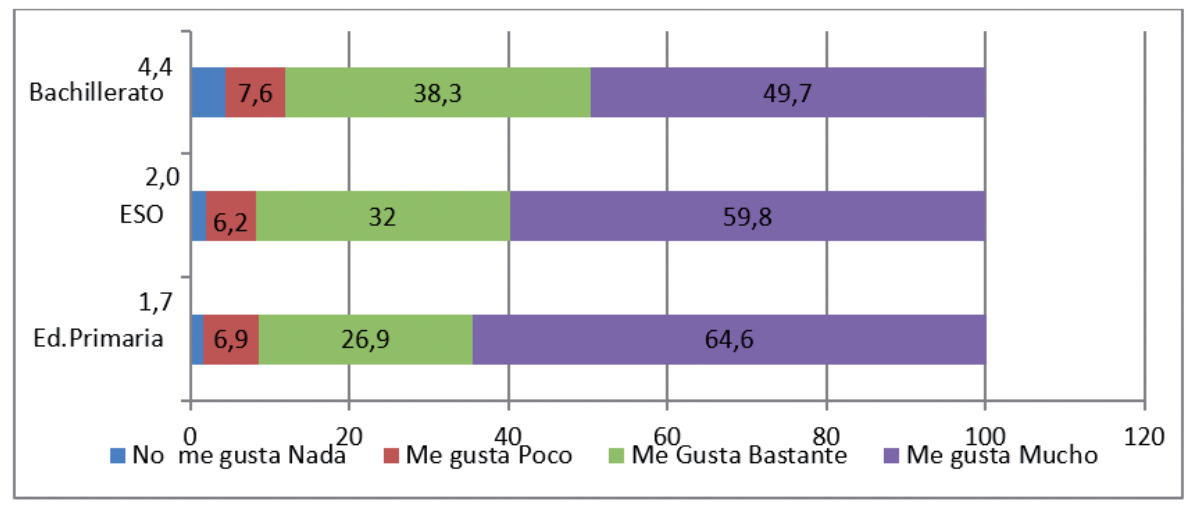

Figura 3. Valoración del uso de las TIC en el aula.

Existe también una relación estadísticamente significativa entre la etapa cursada y la frecuencia de uso que los alumnos y alumnas prefieren dar a las TIC en el aula. (Chi cuadrado $\rho<0.001$; Coeficiente de Contingencia: $0.074 ; \rho<0.001)$. El porcentaje del alumnado de ESO que prefiere usar las TIC todos los días supera al de las otras etapas (Figura 4). No obstante, más del $50 \%$ de los alumnos y alumnas señala su preferencia por usar las TIC todos los días, y entre un 35-41\%, varios días a la semana. 
El uso escolar de las TIC desde la visión del alumnado de Educación Primaria, ESO y Bachillerato

Manuel Area Moreira, Olga Cepeda Romero y luis feliciano garcía

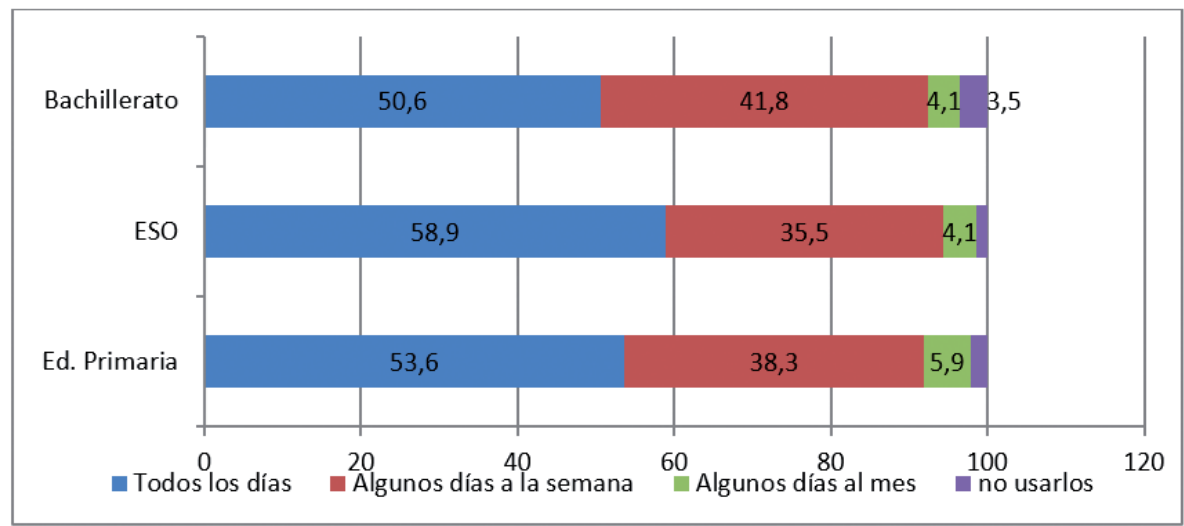

Figura 4. Preferencias sobre frecuencia de uso de las TIC en el aula.

Aunque a más de la mitad de los y las estudiantes siempre les gusta estudiar con TIC, existen relaciones estadísticamente significativas entre la motivación hacia el uso de los recursos tecnológicos y la etapa cursada (Chi cuadrado $\rho<0.000$; Coeficiente de Contingencia: 0.087; $\rho<$ 0.000). El porcentaje de alumnos que señala que siempre le gusta usar las TIC en el aula disminuye de Ed. Primaria a Bachillerato. (Figura 5).

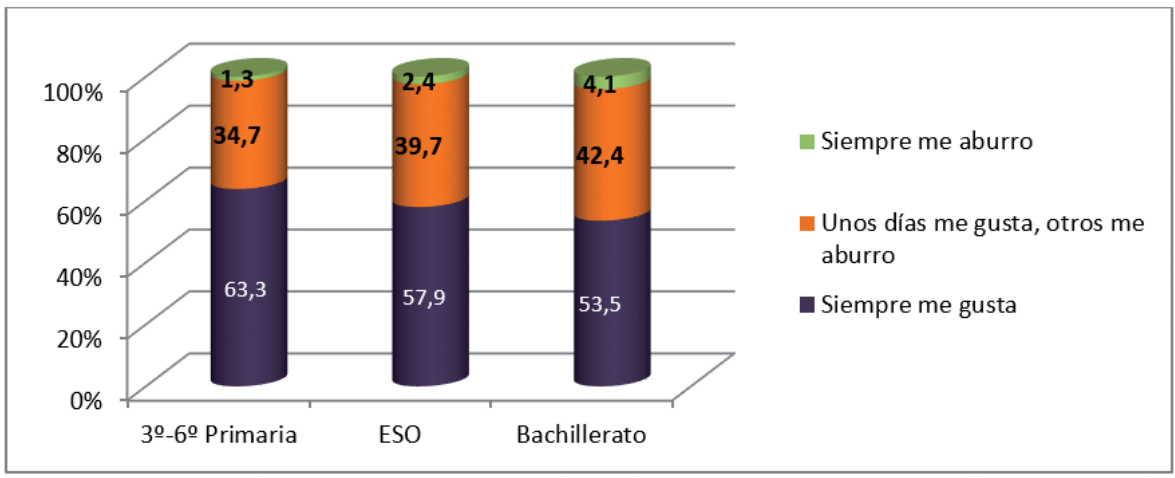

Figura 5. Valoración del trabajo con las TIC.

Actividades CON TIC DESARROlLadAS EN LA CLASE

Existe una tendencia relacional estadísticamente significativa (Chi cuadrado $\rho<0.000$; Coeficiente de Contingencia: 0.090; $\rho<0.000)$, según la cual la realización de actividades o ejercicios on line disminuye notablemente conforme aumenta la etapa cursada por el alumno (Figura 6). 


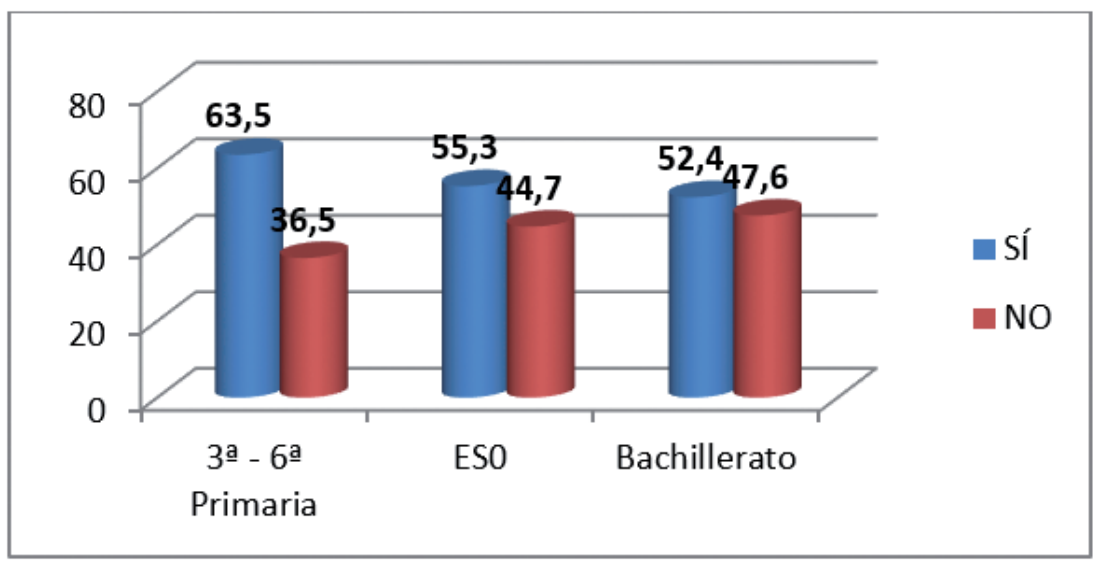

Figura 6. Realizar actividades on line.

Lo mismo ocurre con relación a la elaboración de trabajos en formato digital que disminuye conforme aumenta la etapa cursada por el alumno (Chi cuadrado $\rho<0.050$; Coeficiente de Contingencia: 0.045; $\rho<0.050$. Tendencia que se repite la realización de actividades usando la pizarra digital (Chi cuadrado $\rho<0.000$; Coeficiente de Contingencia: 0.372; $\rho<0.000$ ).

COMPETENCIA DIGITAL PERCIBIDA EN EL PROFESORADO Y EL ALUMNADO.

Existen relaciones estadísticamente significativas entre la percepción que el alumnado tiene sobre el conocimiento que tienen sus profesores de los recursos tecnológicos y la etapa cursada (Chi cuadrado $\rho<0.000$; Coeficiente de Contingencia: 0.348; $\rho<0.000)$. Esta percepción disminuye con la etapa: en Primaria es "Mucho", en ESO "Bastante" y en Bachillerato "Poco" (Figura 7).

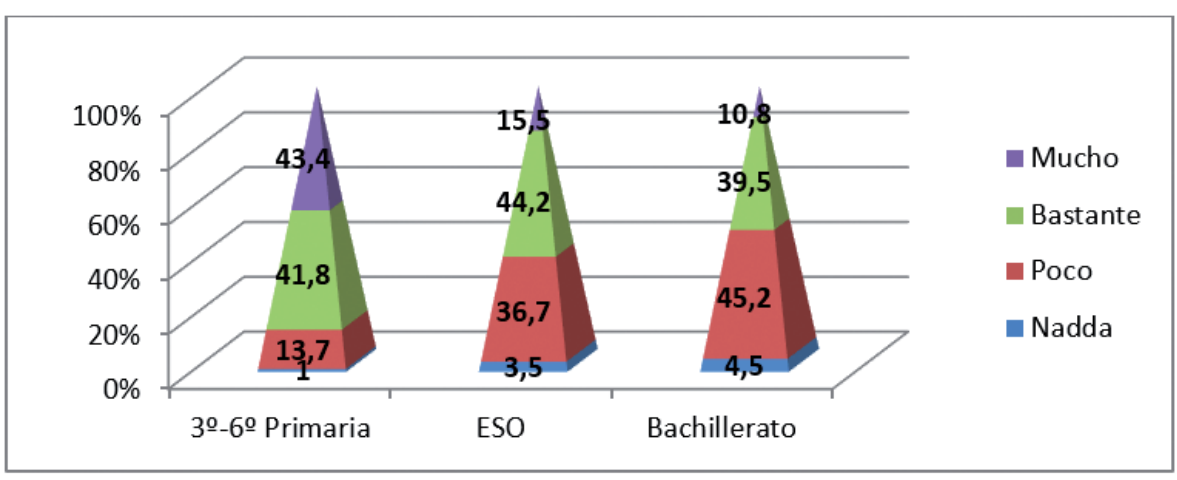

Figura 7. Competencia digital percibida en el profesorado. 
El uso escolar de las TIC desde la visión del alumnado de Educación Primaria, ESO y Bachillerato

Manuel Area Moreira, Olga Cepeda Romero y luis feliciano garcía

Se observan relaciones estadísticamente significativas entre la percepción del alumnado sobre el conocimiento de sus compañeros de los recursos tecnológicos y la etapa (Chi cuadrado $\rho<0.000$; Coeficiente de Contingencia: $0.173 ; \rho<0.000)$. La percepción de competencia digital de los compañeros aumente de Ed. Primaria a Bachillerato (Figura 8).

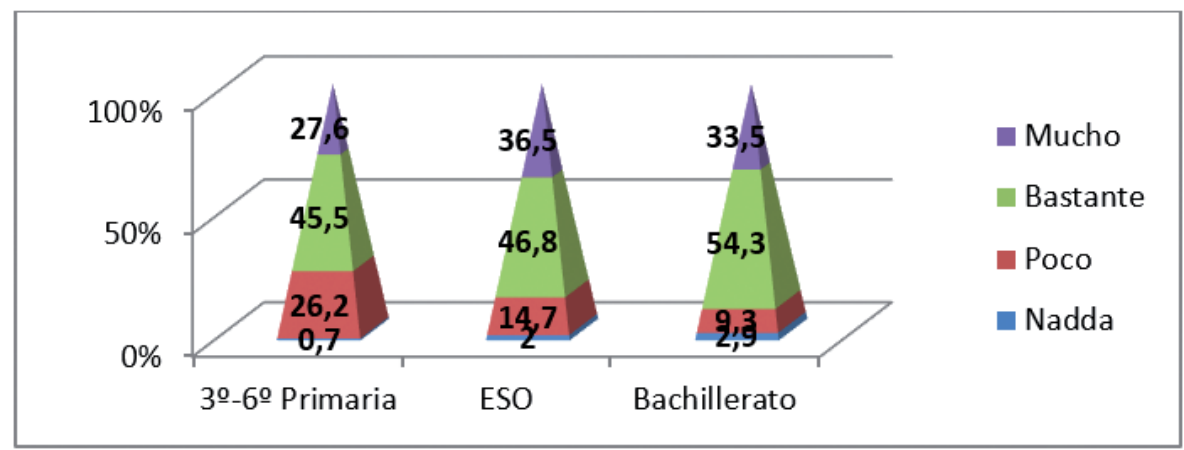

Figura 8. Competencia digital percibida en el alumnado.

Existen relaciones estadísticamente significativas entre la percepción del alumnado sobre el uso adecuado de las TIC por el profesorado para enseñar y la etapa cursada (Chi cuadrado $\rho<0.000$; Coeficiente de Contingencia: $0.282 ; \rho<0.000$ ). Esta percepción disminuye con la etapa (Figura 9).

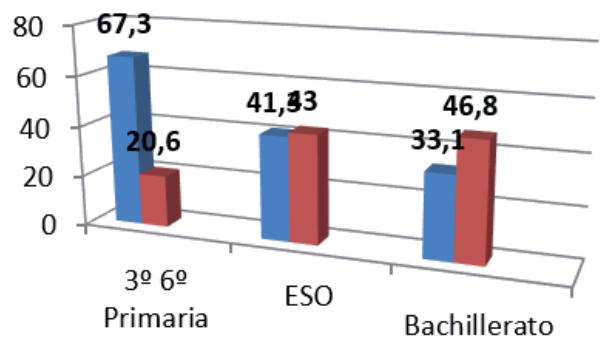

- La mayoría lo domina

- Sólo algunos

- La mayoría no lo domina

No lo sé

Figura 9. Uso adecuado de las TIC por el profesorado para enseñar.

\subsection{Resultados en función del género}

VALORACIÓN DEL USO DE RECURSOS TECNOLÓGICOS EN CLASE

Hay relaciones significativas entre el género y la opinión del alumnado 
sobre el uso de recursos tecnológicos en clase (Figura 10). El 91,9\% del alumnado masculino y el $90,7 \%$ del alumnado femenino opinan que le gusta bastante o mucho utilizar los recursos tecnológicos en clase. El $8,1 \%$ del alumnado masculino y el $9,2 \%$ del alumnado femenino opinan que le gusta poco o nada el uso de recursos tecnológicos en clase.

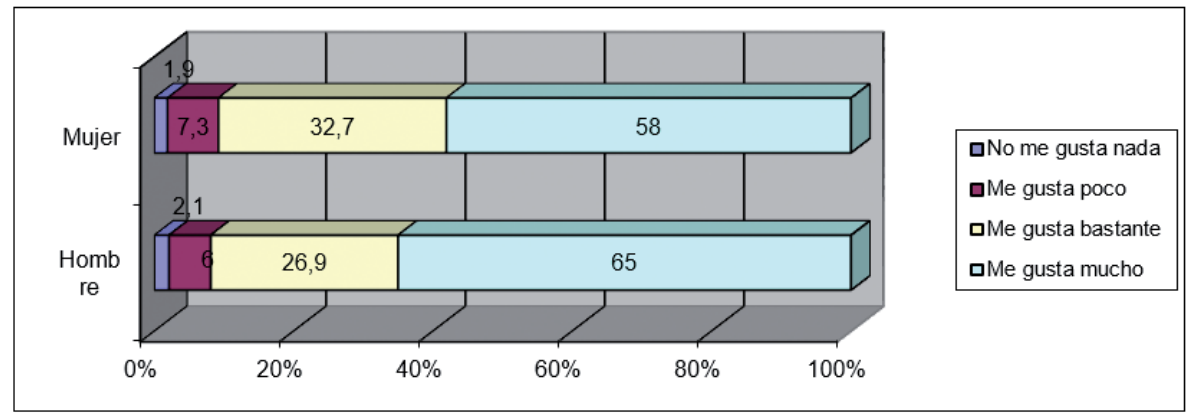

Figura 10. Valoración del uso de recursos tecnológicos en clase.

(Chi cuadrado $\mathrm{p}<0.000$; Coeficiente de Contingencia: 0.074, $\mathrm{p}<0.000$ ).

\section{Preferencias respecto a la frecuencia de uso de las TIC en CLASE}

Hay relaciones significativas entre el género y la opinión del alumnado sobre la frecuencia en el uso de los recursos tecnológicos en clase (Figura 11). El porcentaje de varones que prefieren utilizar todos los días las $\mathrm{TIC}$ en clase es superior al de las mujeres.

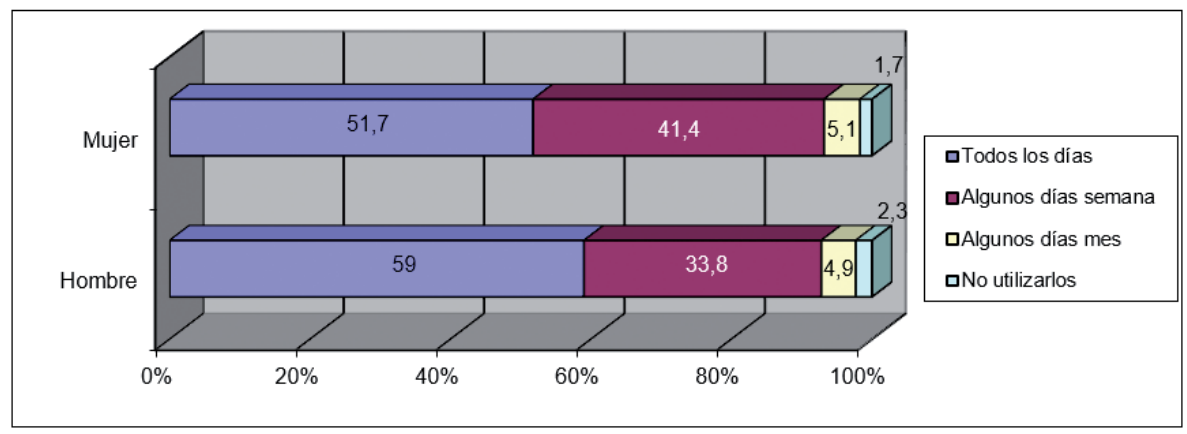

Figura 11. Preferencias respecto a la frecuencia de uso de las TIC en clase. (Chi cuadrado $\mathrm{p}<0.000$; Coeficiente de Contingencia: 0.082, $\mathrm{p}<0.000$ ). 
El uso escolar de las TIC desde la visión del alumnado de Educación Primaria, ESO y Bachillerato

Manuel Area Moreira, Olga Cepeda Romero y luis feliciano garcía

MOtIVACIÓN POR TRABAJAR CON RECURSOS TECNOLÓGICOS EN CLASE

Hay relaciones significativas entre el género y la motivación del alumnado por trabajar con recursos tecnológicos en clase (Figura 12). Existe un mayor porcentaje de varones $(66,8 \%)$ que de mujeres $(54,4 \%)$ en su preferencia o motivación por trabajar con recursos tecnológicos en clase.

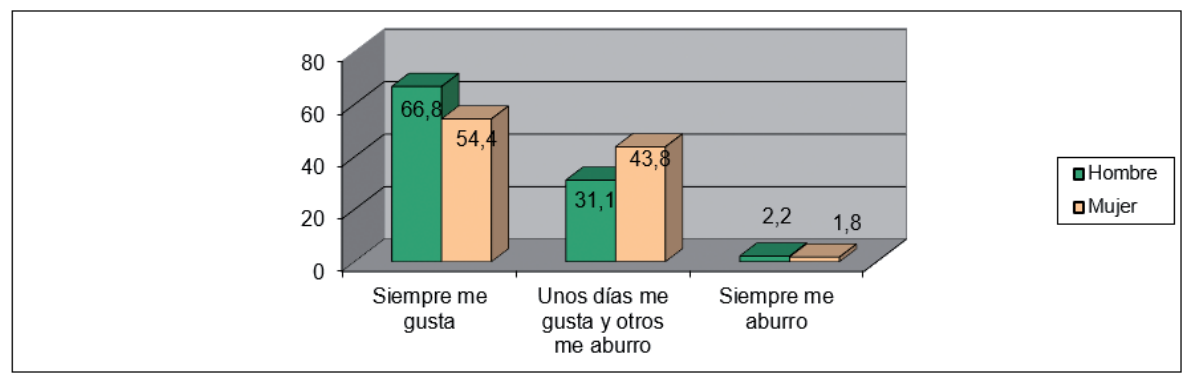

Figura 12. Motivación por trabajar con recursos tecnológicos en clase.

(Chi cuadrado $\mathrm{p}<0.000$; Coeficiente de Contingencia: 0.131, $\mathrm{p}<0.000$ ).

\subsection{Resultados en función de la disponibilidad de TIC en casa}

TECNOLOGÍAS DISPONIBLES EN EL HOGAR

El alumnado, en todas las etapas, dispone de tecnologías digitales en su hogar. El porcentaje de alumnos que tienen TIC en sus casas es ligeramente superior en Bachillerato (Figura 13):

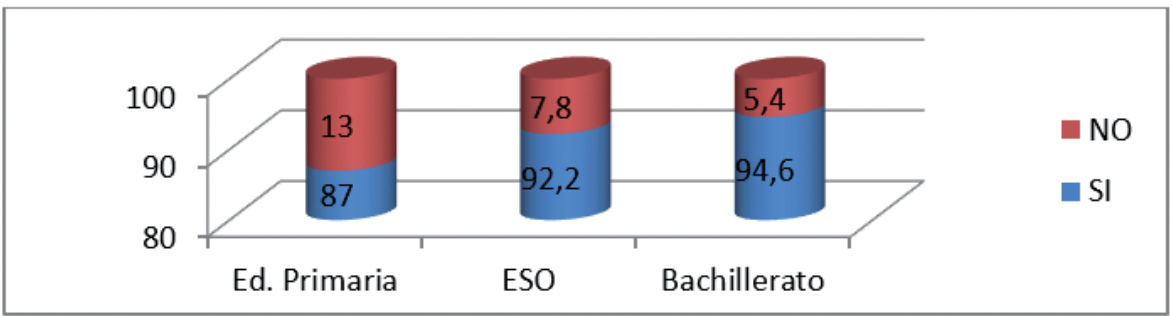

Figura 13. Disponibilidad de Ordenador en el hogar por Etapa.

\section{QUÉ SABEN HACER CON UN ORDENADOR/TABLET}

Se aprecian relaciones significativas entre disponer o no de ordenador para uso personal en casa y saber hacer distintas actividades con ordenador o Tablet. El alumnado que dispone de tecnologías en el hogar sabe realizar más acciones con las TIC en el aula que quienes no las tienen en el contexto familiar (Figura $14 \mathrm{a}, \mathrm{b}$ ): 


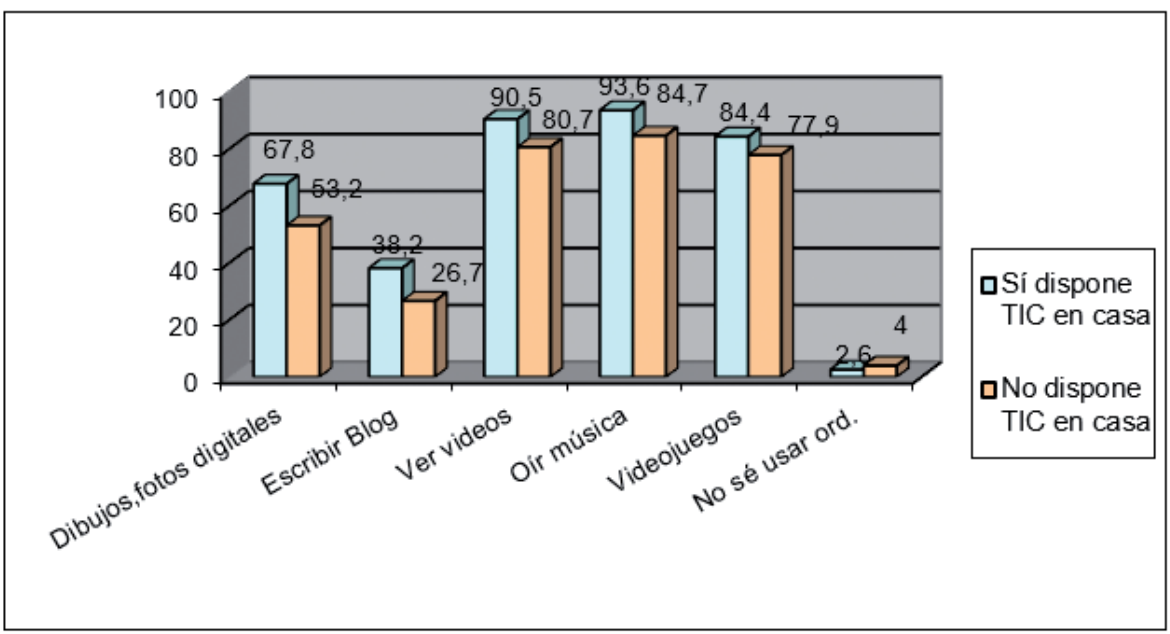

Figura 14a. Saber hacer tareas con un ordenador/tablet.

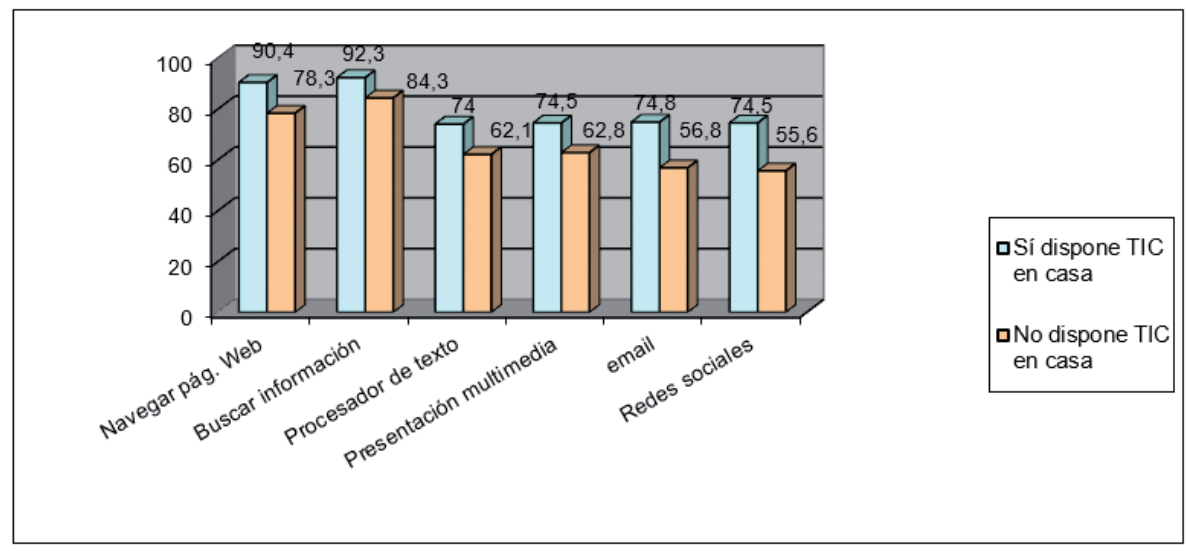

Figura $14 b$. Saber hacer tareas con un ordenador/tablet.

Preferencias sobre la frecuencia de uso de ReCursos tecnolóGicos en Clase

Hay relaciones significativas entre disponer o no de ordenador/tablet para uso personal en casa y la preferencia del alumnado sobre la frecuencia de uso sobre el uso de los recursos tecnológicos en clase (Figura 15). El 93,6\% del alumnado que dispone de ordenador/tablet para uso personal en casa prefiere utilizar los recursos tecnológicos en clase todos los días o algunos días a la semana; este porcentaje es más bajo entre el alumnado que no dispone de ordenador para su uso personal 
El uso escolar de las TIC desde la visión del alumnado de Educación Primaria, ESO y Bachillerato

Manuel Area Moreira, Olga Cepeda Romero y luis feliciano garcía

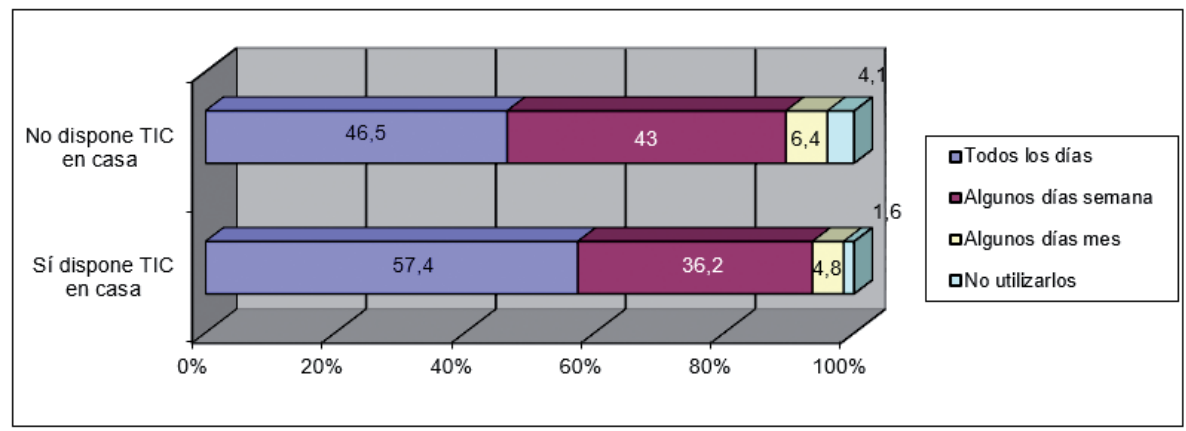

Figura 15. Frecuencia de uso de recursos tecnológicos en clase.

(Chi cuadrado $\mathrm{p}<0.000$; Coeficiente de Contingencia: 0.101, $\mathrm{p}<0.000$ ).

\section{MOtIVACIÓN POR TRABAJAR CON RECURSOS TECNOLÓGICOS EN CLASE}

Hay relaciones significativas entre disponer o no de ordenador para uso personal en casa y el gusto del alumnado por trabajar con recursos tecnológicos en clase (Figura 16). Sólo el 1,5\% y el 4,2\%, respectivamente, manifiestan que se aburren siempre cuando trabajan con recursos tecnológicos en clase. El $62 \%$ y el 55,1\%, respectivamente, afirman que les gusta siempre trabajar con recursos tecnológicos en clase.

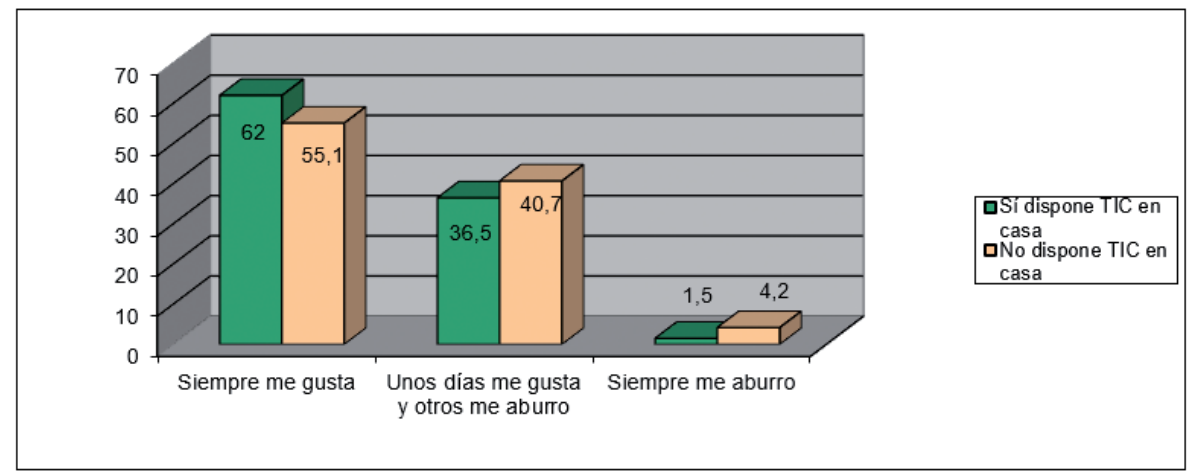

Figura 16. Motivación por trabajar con recursos tecnológicos en clase. (Chi cuadrado $\mathrm{p}<0.000$; Coeficiente de Contingencia: 0.087, $\mathrm{p}<0.000$ ).

\section{Discusión y conclusiones}

Hemos encontrado que actualmente en el contexto del hogar del alumnado existe abundante tecnología digital en cifras que superan el 80- 
90\% (como es el caso de disponibilidad de ordenadores, conexión a Internet, telefonía móvil y TV digital, y en menor medida las tablets). Este hecho ratifica la omnipresencia de las TIC en la vida cotidiana, que éstas ya son accesibles a todas las capas sociales y que están disponibles en todas las islas del archipiélago. La primera evidencia es que la inmensa mayoría de estudiantes que actualmente cursan los estudios de Educación Primaria, ESO y Bachillerato en Canarias son una generación familiarizada desde sus primeros años con la tecnología digital en el contexto del hogar. Son exponente de la denominada generación Z.

Esto se está traduciendo en que casi la totalidad del alumnado encuestado afirma que saben utilizar los ordenadores, aunque lógicamente existen diferencias entre edades de modo que los alumnos de Bachillerato y ESO señalan que dominan más la realización de acciones como navegar por la web, buscar información, producir documentos digitales, comunicarse con amigos en redes sociales, oír música, ver videos, elaborar presentaciones multimedia, retocar fotografías digitales, entre otras. Dicho en pocas palabras, la actual generación de estudiantes, al menos en el contexto escolar de Canarias, dispone de las competencias instrumentales para uso de las herramientas digitales más usuales.

Otra evidencia es que en el hogar no se están produciendo diferencias de disponibilidad a la tecnología entre alumnado masculino y femenino. Es decir, tanto los niños y niñas como los varones y mujeres adolescentes tienen acceso a las mismas en el contexto de casa sin que hayamos encontrado diferencias significativas por género. Asimismo, tampoco encontramos diferencias relevantes entre lo que saben hacer los niños y niñas con los ordenadores (navegar y visitar páginas web, buscar información, escribir con un procesador de texto, elaborar presentaciones multimedia enviar y recibir correo electrónico, comunicarse en redes sociales, o ver videos o películas). Aunque hemos encontrado diferencias con relación a las acciones de oír música y manipular imágenes digitales (a favor de las niñas) frente a escribir en blog o jugar a videojuegos donde los varones obtienen puntuaciones levemente superiores.

Sin embargo, las diferencias más significativas entre varones y mujeres se producen con relación a la valoración del uso educativo de las TIC en el contexto académico. Los niños y los adolescentes varones manifiestan que prefieren usar las TIC en clase, casi todos los días, en todos los cursos y que les gusta hacerlo más que sus compañeras femeninas donde señalan -en mayor proporción que los varones- que se aburren cuando 
las utilizan en clase. No podemos señalar las causas de estas diferencias, aunque intuimos que puedan deberse a razones más estructurales (como puede ser que la lógica computacional ha estado dominada a lo largo de muchas décadas por el pensamiento masculino) que propiamente pedagógicas. Esta es una hipótesis para seguir explorando en el futuro, más que una conclusión derivada de este estudio. Lo que sí podemos sugerir, es que en el contexto del aula el profesorado debe estar atento a estas diferencias de modo que plantee y motive a su alumnado femenino para la cumplimentación de tareas con TIC.

Otro resultado relevante es que la mayoría de los estudiantes, de todas las edades, sin diferencias en el género, de todos niveles educativos y de todas las islas manifiestan que prefieren usar todos los días las TIC en clase, que cuando las utilizan les gusta hacerlo y que las actividades realizadas con las mismas tienen impacto sobre su aprendizaje. Esta conclusión general hemos de matizarla indicando que esta predisposición favorable hacia las TIC varía en función de la etapa cursada. De este modo, hemos encontrado que el alumnado de Educación Primaria tiene una opinión y valoración más positiva hacia las tecnologías que el alumnado de Bachillerato.

Otro de los hallazgos más destacables es que aquellos alumnos que disponen de tecnología en el hogar (ordenador, conexión a Internet, videojuegos,...) tienden a tener una opinión más favorable a desarrollar actividades en clase con las TIC. En concreto, los estudiantes que tienen tecnología en su casa son los que prefieren utilizar los ordenadores todos los días, opinión que se repite en todos los cursos y niveles educativos, y además consideran que las TIC tienen un impacto favorable sobre su aprendizaje. Este resultado confirma, una vez más, que la "brecha digital" puede ser un factor de desigualdad educativo en el sentido de que aquellos estudiantes que provienen de ambientes con abundancia tecnológica en el hogar tienen una predisposición más favorable a aprender con tecnología en el contexto escolar.

De todo lo anterior podemos inferir que la accesibilidad a la tecnología en el hogar no está condicionada preferentemente por cuestiones de género (como sucedía en años anteriores), sino por motivos económicos. Lo cual, una vez más, ratificaría la necesidad de que el sistema escolar público incorpore las TIC a las aulas no sólo con fines pedagógicos, sino también con fines de compensación de las desigualdades sociales de acceso a la tecnología ya que seguramente será en el contexto escolar 
donde muchos estudiantes puedan interaccionar con las mismas con fines culturales.

Es interesante señalar que los estudiantes tienen una visión notoriamente diferenciada de la competencia digital de su profesorado en función de su edad y etapa educativa. Así, los alumnos de Educación Primaria (es decir, niños y niñas entre los siete y doce años) perciben que su profesorado está mejor capacitado que ellos para el uso de las TIC y que la mayoría de los docentes están cualificados para enseñar con TIC. Sin embargo, esta percepción cambia radicalmente a medida que la edad del alumnado aumenta de forma que tanto los estudiantes de la ESO como del Bachillerato opinan que su profesorado dispone de menos competencias digitales que los alumnos, y que la mayoría de los docentes no saben enseñar con TIC. Todo ello nos remite a la ya conocida división entre los "nativos" digitales (los estudiantes) frente a los "emigrantes" digitales (el profesorado) de forma que los adolescentes -que nacieron, se criaron y viven cotidianamente con tecnología- se autoperciben con mayor dominio de las mismas que su profesorado adulto. Esto, evidentemente, pudiera tener consecuencia para la "pérdida de la autoridad" docente cuando se plantean realizar actividades académicas con TIC, de forma que los profesores manifiesten torpeza en su uso como herramientas. Por ello, lo relevante debiera ser trasladar al profesorado de ESO y Bachillerato la necesidad de su capacitación como usuarios de múltiples y variadas herramientas que tienen potencial de uso educativo.

Debemos señalar que el conjunto de resultados expuestos responde a la población de los niños y adolescentes de Canarias, pero de algún modo, con los matices oportunos, éstos pudieran ser extrapolables a los de otras comunidades autónomas, y en consecuencia, al conjunto de España. Las cifras de penetración de las TIC en los hogares canarios es similar al de otras comunidades autónomas españolas (Fundación Telefónica, 2017). Asimismo, muchos de los rasgos encontrados en el alumnado encuestado responde a las características de los Millenials y de la generación Z (Espín, 2015; Espiritusanto, 2016).

En definitiva, podemos concluir que la inmensa mayoría del alumnado de Educación Primaria y Secundaria de nuestro país, al menos de la muestra de Canarias, es una generación familiarizada con la tecnología digital, que está motivada y demanda el uso escolar continuado de las TIC. En este sentido, la etapa, es decir la edad del alumnado, influye notablemente en las percepciones y valoraciones de las distintas variables 
de uso educativo de las tecnologías, de forma que a mayor edad existe una visión más crítica de la competencia digital del profesorado y de las actividades didácticas desarrolladas con las TIC.

Finalmente sugerimos que, además de estudios de encuesta, es necesario seguir profundizado sobre el imaginario del alumnado con el desarrollo de estudios cualitativos de diverso tipo (narrativas audiovisuales, estudios de caso, biografías, entrevistas grupales, entre otras). Ambos enfoques metodológicos se complementan ya que el conocimiento que obtengamos nos permitirá comprender cómo los estudiantes de las distintas etapas educativas perciben y valoran sus experiencias digitales en el contexto escolar. Ese conocimiento nos permitirá fundamentar racionalmente la planificación e implementación de políticas educativas que no sólo se circunscriban a la dotación de recursos tecnológicos a las aulas, sino que principalmente impulsen la innovación pedagógica tanto de las metodologías de enseñanza como de los conocimientos y actitudes del profesorado. El reto, en definitiva, es que las escuelas proporcionen al alumnado del siglo XXI experiencias de aprendizaje de calidad educativa en el marco de la sociedad y cultura digital (Escudero, 2014).

\section{Reconocimientos}

Este artículo se deriva del proyecto La integración educativa de las TIC en el sistema escolar de Canarias. Informe final de evaluación TSP (Tecnologías al Servicio de las Personas). Consejería de Educación, Deportes y Sostenibilidad-Fundación General de la Universidad de La Laguna, desarrollado por el grupo de investigación EDULLAB (Laboratorio de Educación y Nuevas Tecnologías) de la Universidad de La Laguna durante 2014-2015.

\section{Referencias bibliográficas}

Albirini, A. (2006). Teachers' attitudes toward information and communication technologies: the case of Syrian EFL teachers. Computers and Education, 47, 373-398.

Area, M.; Sanabria, A. L. y Vega, A.Mª (2013): Las políticas educativas TIC (Escuela 2.0) en las Comunidades Autónomas de España desde la visión del profesorado. Revista Campus Virtuales, 01, II, pgs. 74-88. 
El uso escolar de las TIC desde la visión del alumnado de Educación Primaria, ESO y

Bachillerato

Manuel Area Moreira, Olga Cepeda Romero y luis feliciano garcía

Area, M. y Sanabria, A.L. (2014). Opiniones, expectativas y valoraciones del profesorado participante en el Programa Escuela 2.0 en España. Revista Educar, vol 50, No 1, pgs. 15-39. doi: http://dx.doi.org/10.5565/rev/educar.64

Area, M.; Borrás, J. y Sannicolás, B. (2015): Educar a la generación de los Millennials como ciudadanos cultos del ciberespacio. Apuntes para la alfabetización digital. Revista Estudios de Juventud, septiembre, 109, 13-32 (monográfico sobre "Juventud Global: Identidades y escenarios de actuación en clave cosmopolita"). Consultado el 10/10/2017 en http://www.injuve.es/sites/default/files/cap1_109.pdf

Area, M. Hernández, V. y Sosa, J. (2016): Modelos de integración didáctica de las TIC en el aula. Comunicar, XXIV, 47, abril 2016, pgs. 79-87, http://dx.doi.org/10.3916/ C47-2016-08

Balanskat, A, Blamire, R. y Kefala, S, (2006): The ICT Impact Report. A review of studies of ICT impact on schools in Europe. European Schoolnet. European Comission. Consultado 23/1/2018 en https://ictedupolicy.org/content/ict-impact-report-reviewstudies-ict-impact-schools-europe

Ballesta, F.J.; Cerezo, M.C. y Veas, A. (2014): Los jóvenes de educación secundaria ante el uso y consumo de las TIC. Etic@net, 14 (1),pgs. 22-40.

Bringué, X. y Sádaba, C. (2009). La Generación interactiva en España. Niños y adolescentes ante las pantallas. Madrid: Ariel-Fundación Telefónica.

Buabeng-Andoha, Ch. and Issifub, Y. (2015): Implementation Of ICT In Learning: A Study Of Students In Ghanaian Secondary Schools. Procedia - Social and Behavioral Sciences, 191, pp. $1282-1287$

Colás, P., De Pablos, J. y Ballesta, J. (2018): Incidencia de las TIC en la enseñanza en el sistema educativo español: una revisión de la investigación. RED. Revista de Educación a Distancia, 56, enero 2018. Consultado 1/1/2018 en http://www.um.es/ead/ red/56/colas_et_al.pdf

Conde, S.; Ávila, J.A.; Núñez, L. Mirabent, M. D (2015): Opinión del profesorado y alumnado sobre la implantación, uso y resultados de las TIC en Educación Primaria: evaluación de un centro. REICE: Revista Electrónica Iberoamericana sobre Calidad, Eficacia y Cambio en Educación, 13, (3), págs. 57-75.

De Pablos, J. (Coord.) (2015). Los centros educativos ante el desafío de las tecnologías digitales. Madrid: Ed. La Muralla

Domínguez, R.;Chica, E. y Hernández, A. (2015): Valoración del uso de las tecnologías para el aprendizaje por alumnado de secundaria. Investigar con y para la sociedad, Actas del XVII Congreso Internacional AIDIPE, Vol. 3, págs. 1571-1580. Consultado 22/12/2017 en http://avanza.uca.es/aidipe2015/libro/volumen3.pdf

Drent, M. y Meelissen, M. (2008). Which factors obstruct or stimulate teacher educators to use ICT innovatively? Computers and education, 51, 187-199.

Escudero, J.M. (2014): Contextos, contenidos y dinámicas de innovación educativa: ¿el dónde y el cómo de la Tecnología Educativa? Actas XXII Jornadas Universitarias de Tecnología Educativa. Toledo, junio. Consultada 28/11/2017 en http://www.icono14. es/a-jute-2014

Espín, M. (Coord.) (2015): Juventud Global: Identidades y escenarios de actuación en clave cosmopolita. Revista de Estudios de Juventud, 109, monográfico. Consultado 
El uso escolar de las TIC desde la visión del alumnado de Educación Primaria, ESO y Bachillerato

Manuel Area Moreira, Olga Cepeda Romero y luis feliciano garcía

10/1/2018 en http://www.injuve.es/observatorio/demografia-e-informacion-general/ no-109-juventud-global-identidades-y-escenarios-de-actuacion-en-clave-cosmopolita

Espiritusanto, O. (2016): Los auténticos nativos digitales: ¿estamos preparados para la Generación Z. Revista de Estudios de Juventud, 109, monográfico. Consultado 10/1/2018 en http://www.injuve.es/observatorio/infotecnologia/revista-n-114-los-autenticos-nativos-digitales-estamos-preparados-para-la-generacion-z

Fundación Telefónica (2017): Sociedad Digital en España 2017. Fundación TelefónicaAriel, Madrid. Consultado 6/2/2018 en https://www.fundaciontelefonica.com/arte_ cultura/publicaciones-listado/pagina-item-publicaciones/itempubli/625/

García Galera, M.C. y Fernández, C. (2016): Si lo vives, lo compartes. Cómo se comunican los jóvenes en un mundo digital. Ariel-Fundación Telefónica, Madrid. Consultado 5/12/2017 en https://www.fundaciontelefonica.com/arte_cultura/publicaciones-listado/pagina-item-publicaciones/itempubli/499/

Glusac, D.; Makitan, V.; Karuovic, D; Radosav, D.; Milanov, D. (2015): Adolescents' informal computer usage and their expectations of ICT in teaching. Case study: Serbia. Computers \& Education, 81 (2015), pp. 133-142.

López Fernández, M. C.: (2015): TIC y redes sociales en educación secundaria: análisis sobre identidad digital y riesgos en la red. Investigar con y para la sociedad, Actas del XVII Congreso Internacional AIDIPE, Vol. 3, págs. 1571-1580. Consultado 2/2/2018 en http://avanza.uca.es/aidipe2015/libro/volumen3.pdf

Martínez, R. y Espinar, E. (2012): Adolescentes y tecnologías de la información y la comunicación en España. OBETS. Revista de Ciencias Sociales. Vol. 7, n. ${ }^{\circ}$ 1, 2012; pp. 109-122

Nikolopoulou, K. and Gialamas, V. (2016): Exploring Secondary School Pupils' ICT Engagement: A Validation Study. Creative Education, 2016, 7, pp. 567-573. http://dx.doi. org/10.4236/ce.2016.74059

Raquiman, P. (2014): Representaciones sobre el cambio en el uso de las TIC. Relatos de vida de profesores. Revista Iberoamericana de educación, 65, 2014.

Reig, D. y Vilches, L.F. (2013): Los jóvenes en la era de la hiperconectividad: tendencias, claves y miradas. Fundación Telefónica/Fundacion Encuentro, Madrid. Consultado 14/12/2017 en https://www.fundaciontelefonica.com/arte_cultura/publicaciones-listado/pagina-item-publicaciones/itempubli/182/

Rodríguez, E. y Megías, I. (2014): Jóvenes y comunicación. La impronta de lo virtual. Centro Reina Sofía sobre Adolescencia, Madrid.

Ruiz, J. y Sánchez, J. (2007): El impacto del proyecto de centros TIC desde la experiencia vivida por el alumnado. Pixel-Bit. Revista de Medios y Educación, 30, julio, pp. 143150.

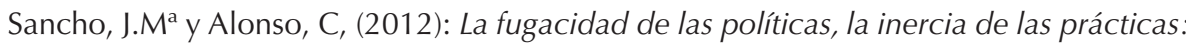
la educación y las técnicas de la información y la comunicación. Octaedro Editorial, Barcelona.

Selwyn, N. Potter, J. and Cranmer, S. (2009): Primary pupils' use of information and communication technologies at school and home. British Journal of Educational Technology Vol 40 No 52009 919-932. doi:10.1111/j.1467-8535.2008.00876.x 
El uso escolar de las TIC desde la visión del alumnado de Educación Primaria, ESO y

Bachillerato

Manuel Area Moreira, Olga Cepeda Romero y luis feliciano garcía

Sigalés, C., Josep, M., Mominó, J., Meneses, J., \& Badia, A. (2008): La integración de Internet en la educación escolar española: Situación actual y perspectivas de futuro. Fundación Telefónica/ IN3-UOC. Consultado 30/12/2018 en https://www.researchgate.net/publication/264368576_La_integracion_de_internet_en_la_educacion_escolar_espanola_situacion_actual_y_perspectivas_de_futuro

Solano, I.M.; González, V. y López, P. (2013): Adolescentes y comunicación: las TIC como recurso para la interacción social en Educación Secundaria. Pixel-Bit. Revista de Medios y Educación, 42, enero, pp. 23-35.

Sonlleva. M., Torrego, A. y Martínez, S. (2017): Es una locura vivir sin Facebook ni WhatsApp": la huella tecnológica en el docente en formación. edmetic, Revista de Educación Mediática y TIC. 6(2), pgs. 255-276. Cosultado el 7/11/2017 en doi: https://doi. org/10.21071/edmetic.v6i2.6935

Souto, X.M.; Jardón, P, Traver,N.; Solbes, J. y Ramírez, S. (2004): Visión del alumnado de las TIC y sus implicaciones sociales. Investigación en la escuela, 54, pgs. 81-92.

Tejedor, J. y García-Valcárcel, A. (2006): Competencias de los profesores para el uso de las TIC en la enseñanza: análisis de sus conocimientos y actitudes. Revista española de pedagogía, 64 (233), págs. 21-43.

Umar, I.N. and Jalil, N. (2012): ICT skills, practices and barriers of its use among secondary school students. Procedia - Social and Behavioral Sciences 46, pp. 5672 - 5676. Consultado 11/12/2017 en https://www.researchgate.net/publication/271609705_ ICT_Skills_Practices_and_Barriers_of_Its_Use_Among_Secondary_School_Students

Vázquez, T., Sánchez, M. y Frutos (2017): Autopercepción de la competencia digital de profesores de educación primaria y secundaria de la Comunidad de Madrid e identificación del uso de las TIC en su práctica docente. En F.J. Herrero Gutiérrez, Mateos, C. (Coord): Del verbo al bit. Revista Latina de Comunicación Social, Universidad de La Laguna, págs. 1208-1226. Consultado 21/1/2018 en http://www.revistalatinacs. org/16SLCS/libro-colectivo-edicion-2.html

Zhang, H. and Zhu, C. (2016): A Study of Digital Media Literacy of the 5th and 6th Grade Primary Students in Beijing. Asia-Pacific Educational Research, 25(4), pp. 579-592. DOI 10.1007/s40299-016-0285-2 
